\title{
UNA CULTURA \\ PARA \\ EMBALSAMAR
}

Pascal Bruckner*

No es fácil ser un heredero, y en París menos que en otros lugares. En esta ciudad que realizó en Francia una verdadera captación y una nacionalización del pensamiento, en este enclave cosmopolita que parece concentrar entre sus muros toda la sustancia reflexiva y espiritual del país, nos vemos sin cesar remitidos al recuerdo de los grandes antepasados que vivieron antes que nosotros. Somos los deudores eternos frente a aquéllos que nos abrieron el camino y a quienes debemos superar o, al menos igualar. Pensemos tan sólo, para no tomar más que un período corto, en el historial de los escritores de la postguerra, en los seis premios Nobel que Francia obtuvo desde 1946 hasta 1985: Gide, Camus, Mauriac, Saint-John Perse, Sartre, Simon. Un patronato tan imponente puede estimular o deprimir, puede transformar a los autores y artistas en rentistas preocupados por manejar la herencia, por bordar amables variaciones sobre los temas ya explorados.

La ciudad está enteramente impregnada de materia literaria, poética, pictórica, novelesca; nos paseamos entre las páginas de una antología que mezcla lo sublime, lo grotesco, lo lírico, lo íntimo. Cada plaza, cada café, cada casa nos remiten a la imagen de uno de esos gigantes, que nos abruman con sus rasgos ingeniosos, con sus intuiciones, con sus descubrimientos fulgurantes. ¿Acaso no ha sido siempre así? Por supuesto.

* Traducción de Silvia Pasternac. 
Pascal Bruckner

Entonces cada generación prosperaba sobre la negación de la anterior; refutar a los predecesores antes de ser uno mismo, ser anulado por sus sucesores se volvió incluso una especie de escuela. Esto fue llamado."la tradición de lo nuevo", y toda la modernidad se ha reconocido en dicho ejercicio.

Por lo tanto, el rechazo de la modernidad se realizó en nosotros bajo el signo de la fatiga, no el de la rebelión: no fuimos educados con la oposición furiosa de nuestros mayores, sino con una especie de cansancio frente a las búsquedas formales, a las consignas que les eran propias. Abandonamos, entonces, los mitos sobre los cuales ellos vivían, ya no compartimos más su inquebrantable confianza en las relaciones que deberían unir al Arte con la Política, con el Progreso, con la Historia, los tres encaminados hacia la misma meta: la emancipación de la humanidad. Ya no creemos, como los surrealistas, en el matrimonio de la poesía con la revolución; como los existencialistas, en la necesidad de una literatura comprometida; como el "nouveum roman" o el movimiento de Tel quel, en las virtudes de la vanguardia. Predicamos el retorno: retorno a la intriga, a los personajes, a la melodía, a la moral, al humanismo. Desconfiamos de los sortilegios de la tabla rasa, de la ruptura, de la experimentación sistemática, que con mucha frecuencia son sinónimos de aburrimiento, de gratuidad, de terrorismo. Pensemos vagamente que el arte debe estar al servicio de una verdad, pero ya no sabemos cuál, ni siquiera si existe. Finalmente, se ha roto la antigua solidaridad que ligaba a la literatura con la música, la pintura, el cine, y permitía que estas diferentes disciplinas se fecundaran unas a otras. No más pureza, sino un eclecticismo sonriente; no más leyes de hierro, sino una tolerancia absoluta; no más escuelas o grupos, sino autores dispersos; no más combate por librar a través de los libros, lienzos, pantallas o partituras, sino simples emociones.

\section{Una entre otras}

En resumen, pensábamos que habíamos puesto a esos viejos en su lugar, que habíamos enterrado completamente a estos muertos con el fin de 
retomar su sucesión de la manera más lógica. Pero aparece una sospecha aquí, una sospecha terrible, insinuadora, y que el extranjero nos repite a cada momento: ya no está pasando nada esencial entre nosotros; París estaría usurpando su leyenda. Se Labría roto un eslabón en el engendramiento continuo de las formas: los hijos ya no serían dignos de sus padres, no habría sucedido otra cosa que el vacío tras la extraordinaria efervescencia de los años cincuenta, sesenta, setenta. No importa si es verdad o mentira, el rumor ya es con mucho una certidumbre.

La modernidad ha muerto de agotamiento, de una carrera por la novedad que resultó ser una carrera hacia el abismo. Pero, antes de desaparecer, produjo algunas joyas. ¿Y cómo no ponerse nostálgico con las posibilidades fascinantes que reveló, con los grandes descubrimientos que marcaron sus tiempos más bellos? Algunos se consuelan diciendo que nuestros antecesores no eran tan grandes, que Gide, Sartre, Camus, Robbe-Grillet, Foucault, Barthes, a fin de cuentas... Triste pretexto: pues estos modernos resisten bien y siguen haciéndonos sombra. Y su infranqueable cohorte parece cerrarnos el paso no solamente a la notoriedad, sino a la existencia misma: no basta con el hecho de que vengamos después de ellos, no es seguro que los reemplacemos. Si vamos a Roma, a Madrid, a Nueva York, a Berlín, siempre es de ellos de quienes se habla; la gloria y la grandeza de París se asocia con sus nombres. Preminencia injusta puesto que, por más desapegados que estemos de la idea de un sentido de la Historia o de un progreso de las artes, ambicionamos, como en todas las épocas, dejar una huella, marcar nuestro tiempo (y la postmodernidad, en el fondo, quizás no es otra cosa que un avatar flexible y sofisticado de la modernidad con la cual comparte la misma concepción lineal del tiempo, menos el dogmatismo, más la ironía hacia uno mismo).

Entendámonos: como en el pasado, París canta más que ninguna otra ciudad la suerte de pertenecer a una nación literaria, de ser la cabeza de la República de las letras. En ningún lugar el fervor por los debates, el gusto por la abstracción, por la dramaturgia intelectual están desarrollados como aquí, hasta la caricatura. Podemos reír, y debemos reír, del parisianismo -esta mezcla de retórica, de pedantería y de frivolidad-; pero es la contrapartida de una vida espiritual sin equivalente, que no se queda inclinada dentro de círculos limitados, sino que prorrumpe fre- 
Pascal Bruckner

cuentemente entre el gran público culto. Una especie de división internacional del trabajo parece habernos atribuido a nosotros los franceses la fabricación en serie de las ideas. En París, vivimos las ideas como pasiones, con entusiasmos violentos y abandonos instantáneos; nos gustan los bellos discursos, las palabras raras, los períodos bien enloquecidos; producimos fórmulas como otros producen albúmina o colesterol.

Sn embargo, si bien toda comunidad intelectual se estructura alrededor de una controversia, es necesario confesar que muchas de las discusiones que nos agitan son tan estrechamente hexagonales ${ }^{1}$ que no fomentan la exportación. Se terminó el período en que París hacía vivir al mundo al ritmo de sus hombres y de sus caprichos, cuando podía todavía dictar su ley a las élites cultas de las otras naciones, cuando el desplazamiento de una coma, una rima particularmente audaz, hacían estremecerse a los jóvenes hasta Rio o Buenos Aires. No es que la literatura, la filosofía, la pintura, la música sean en realidad más malas aquí que en otros lugares; en todo caso, ya no son las mejores. París se volvió una capital entre otras. No hubo borramiento, sino nivelación: ninguna otra ciudad la ha reemplazado en su papel de metrópolis, pero París dejo de ser irremplazable.

Así, se entiende que tantos discursos sobre la cultura prefieran acusar 22 a los medios, al gobierno, a la publicidad, a la escuela de conspirar por el descenso del nivel intelectual de los franceses, ante que mirar la verdad de frente. Estas jeremiadas tienen un valor de síntomas: dejan ver claramente nuestra duda en cuanto a la fecundidad literaria y artística actual de los franceses. La cultura está evidentemente ligada a la transmisión y a la difusión: pero sólo la creación asegura la grandeza y permite que la vida del espíritu vaya un poco más allá de ella misma. Y es sobre esta capacidad creadora que recae hoy, con razón o sin ella, esta sospecha. Tenemos la sensación, sin duda injusta, de que nada grande, nada nuevo puede aparecer. Si hay una declinación de la influencia francesa en el territorio de las artes y de las humanidades, la culpa es de todos nosotros, en tanto que colectividad, y no de algún oscuro complot urdido

${ }^{1}$ Los franceses se refieren a su propio país como "el hexágono", haciendo alusión a la forma del territorio. 
UNA CULTURA DEL EMBALSAMIENTO

por las cancillerías o sobre los canales de televisión. Agreguemos, para dar más de la medida, que los reproches con que nos agobian en el extranjero provienen más que nada de una espectativa frustada; con relación a la extraordinaria inventiva de los treinta gloriosos, nuestro período parece marcado por la calma relativa o incluso por la inercia.

\section{El deber de irreverencia}

Y quizás nos encontramos aquí remitidos a las fuentes de nuestro malestar: estamos colocados en París en la posición de ser los conservadores de un tesoro pasado más que los inventores de un tesoro por venir. París se vuelve año con año una ciudad más bella, más acogedora; pero su belleza es también la de un museo: veneramos entre sus muros una verdadera religión de la cultura, con sus grandes sacerdotes, sus empleados, sus profetas, optimistas o pesimistas. Por todas partes, la preservación prevalece sobre la imaginación y el descubrimiento; sufrimos, en esta ciudad demasiado rica, de un exceso de memoria, de una hipertofria del sentido histórico. Y las obras que se publican hoy ya no tienen siquiera el atractivo del fruto prohibido; nos dan satisfacciones elevadas y delicadas pero ninguna agita nuestro psiquismo, pues la hora del derrumbamiento de los tabúes y de las revoluciones formales parece cerrado por el momento. Los escándalos provocados por Hernani (1830), Ubu rey (1896), La consagración de la primavera (1913) o Desiertos, de Varese (1954) son propiamente impensables en nuestros días. Al dejar de ser subversiva (pues no amenaza a ningún poder y ningún poder la amenaza), la cultura en Francia quizá dejó de tener un impacto decisivo. Al ganar la seguridad y el derecho a la libre impresión y circulación de sus obras, los escritores y artistas han perdido una gran fuente de influencia.

Es una paradoja terrible: la represión aplasta a los novelistas a los poetas, pero les da también una fuerza inaudita; la más mínima crítica que hayan puede poner en peligro a los poderes establecidos. Hay casos, entonces, extremadamente raros donde la literatura puede tener la eficacia de una rima; donde la vida de una nación puede confundirse con 
Pascal Bruckner

la de un libro. Pero nuestra libertad es un regalo envenenado que quita responsabilidad a los creadores, autorizados ahora a publicar y a escribir lo que quieran. Es posible que la comodidad democrática sea fatal para las artes. Si todo está permitido, ya nada tiene importancia, y la literatura, la música, la pintura toman la forma, en el mejor de los casos, de un ornamento de buena calidad y, en el peor, de una diversión de buena ley.

Con respecto a esto, París no puede ser otra cosa que el reflejo de Europa occidental, que está también enteramente transformada en un memorial de su propia historia, petrificada en la admiración muda de su pasado. En nuestra época de ecología generalizada, se trata de proteger, de mantener: navegamos en la era de los balances, de la salvaguarda, que es la única que una vez más acapara las energías. La cultura no escapa de este fenómeno: está como embalsamada, momificada; se ahoga literalmente bajo los homenajes. Podemos preguntarnos si, con nuestra piedad, no será el espíritu mismo -es decir, la interrogación, el cuestionamiento, la discusión- el que está marchitándose, aplastado bajo un exceso de elogios y de atenciones. Como si el ataque lo revitalizara, mientras que, al querer protegerlo, como si se tratara de una convalescente, transformamos nuestra extraordinaria reserva de voces, de ideas, de innovaciones, en una necrópolis cuyos habitantes silenciosos permanececen petrificados por nuestra admiración. Claro que la conservaciónd del patrimonio es algo indispensable; $y$, en este plano, Francia -rica en festivales y exposiciones hasta en las comunidades más pequeñas- da pruebas de una singular vitalidad; otorga cuidado y un desvelo completamente conmovedor a la preservación de sus sitios más bellos. Pero una cultura no se puede contentar con celebrar y conmemorar: para seguir viva, también debe deshacerse del lastre de su legado, romper con los usos $\mathrm{y}$, a veces, incluso pisotear sus tradiciones para renovarlas. $\mathrm{Si}$ olvidamos que no hay creación sin irreverencia, sin fervor ni furor polémico, toda Europa, al igual que París, está acechada por la museificación y, envuelta en sus monumentos, sus instintos, sus academias, corre el riesgo de transformarse sin ruido en una Disneylandia de lujo. 